\title{
Acute effects of different levels of continuous positive airway pressure on cardiac autonomic modulation in chronic heart failure and chronic obstructive pulmonary disease
}

Michel S. Reis', Luciana M.M. Sampaio², Diego Lacerda², Luis V.F. De Oliveira², Guilherme B. Pereira ${ }^{1}$, Camila B.F. Pantoni ${ }^{1}$, Luciana Di Thommazo ${ }^{1}$, Aparecida M. Catai ${ }^{1}$, Audrey Borghi-Silva ${ }^{1}$

${ }^{1}$ Cardiopulmonary Physiotherapy Laboratory, Center for Research in Physical Exercise, Federal University of São Carlos, São Paulo, Brazil

2Rehabilitation Sciences Master's Program, Nove de Julho University, São Paulo, Brazil

Submitted: 3 March 2010

Accepted: 21 April 2010

Arch Med Sci 2010; 6, 5: 719-727

DOI: 10.5114/aoms.2010.17087

Copyright $\odot 2010$ Termedia \& Banach

\section{Abstract}

Introduction: Non-invasive ventilation may improve autonomic modulation and ventilatory parameters in severely disabled patients. The aim of the present study was to evaluate the physiological influence of acute treatment with different levels of continuous positive airway pressure (CPAP) on the autonomic balance of heart and respiratory responses in patients with stable chronic obstructive pulmonary disease (COPD) and chronic heart failure (CHF).

Material and methods: A COPD group $(n=10)$, CHF group $(n=8)$ and healthy subjects $(n=10)$ were evaluated. The participants were randomized to receive three different levels of CPAP on the same day: sham ventilation (Sham), $5 \mathrm{cmH}_{2} \mathrm{O}$ (CPAP5) and $10 \mathrm{cmH}_{2} \mathrm{O}$ (CPAP10) for 10 min. Respiratory rate, end tidal carbon dioxide $\left(\mathrm{E}_{\mathrm{T}} \mathrm{CO}_{2}\right)$, peripheral oxygen saturation $\left(\mathrm{SpO}_{2}\right)$, heart rate $(\mathrm{HR})$, blood pressure and heart rate variability in the time and frequency domains were measured during spontaneous breathing and under the sham, CPAP5 and CPAP10 conditions.

Results: All groups experienced a reduction in $\mathrm{E}_{T} \mathrm{CO}_{2}$ values during treatment with CPAP $(p<0.05)$. CPAP increased $\mathrm{SpO}_{2}$ and HR in the COPD group $(p<0.05)$. The COPD group also had lower RMSSD values during treatment with different levels of CPAP when compared to the control group $(p<0.05)$. In the CHF group, CPAP5 and CPAP10 increased the SDNN value $(p<0.05)$. CPAP10 reduced the SDNN value in the COPD group $(p<0.05)$.

Conclusion: The findings suggest that CPAP may cause improvements in the neural control of heart rate in patients with stable COPD and CHF. For each patient, the "best CPAP level" should be defined as the best respiratory response and autonomic balance.

Key words: autonomic nervous system, cardiomyopathy, COPD, CPAP ventilation, non-invasive ventilation.

\section{Introduction}

Autonomic tone is the balance between sympathetic and parasympathetic activity and is responsible for controlling blood pressure $(\mathrm{BP})$, heart rate (HR), heart contractility, ventricular filling time and vascular tone [1]. Autonomic dysfunction increases sympathetic activity and reduces parasympathetic activity, which is related to the physiopathology of some

\author{
Corresponding author: \\ Audrey Borghi-Silva, PhD \\ Cardiopulmonary \\ Physiotherapy Laboratory \\ Center for Research \\ in Physical Exercise \\ Federal University of São \\ Carlos \\ Rodovia Washington Luis, \\ Km 235 \\ CEP: 13565-905, São Carlos \\ São Paulo, Brazil \\ Phone: +55 1633518705 \\ Fax: +55 1633612081 \\ E-mail: audrey@ufscar.br
}


diseases, arrhythmia and an elevated risk of mortality [2, 3].

The determination of autonomic balance through an analysis of R-R intervals offers a simple, non-invasive measure of this component of cardiovascular control. The intrinsic regulation and control of the electrical activity of the heart rate can be modulated by the sympathetic and parasympathetic nervous systems, baroreflex activity, intrinsic cardiac nervous system, cardiopulmonary reflexes and respiration [1].

Alterations in alveolar and intrathoracic pressure and the activity of lung receptors during noninvasive ventilation (NIV) could modulate the balance of autonomic heart rate control [1]. NIV has been used in the treatment of chronic obstructive pulmonary disease (COPD), obstructive sleep apnoea, chronic heart failure (CHF) and asthma [4-8]. Fietze et al. and Garet et al. employed different NIV modalities and found significant changes in intrathoracic haemodynamics, vagal efferent activity and $H R$ in healthy individuals $[9,10]$.

Different modes of continuous positive airway pressure (CPAP) have been related to changes in the activity of the sympathetic nervous system, such as an increase in sympathetic nerve firing in patients with CHF and the parasympathetic activity, improved short and long-term haemodynamic function, electrical remodelling, reduced respiratory muscle work and neurohormonal modulation [7, 1114]. Despite the many studies demonstrating the benefits of NIV, the effects of treatment with CPAP on the autonomic heart rate in patients with $\mathrm{CHF}$ need to be understood better.

Patients with COPD also exhibit sympathovagal imbalance of the autonomic heart rate, which has been related to an elevated risk of cardiovascular events [4, 15-17]. NIV has been used as an adjunct to COPD rehabilitation, as it increases ventilation, allows the respiratory muscles to unload during rest and physical exercise, and reduces symptoms of dyspnoea [18-23]. It has been demonstrated that bi-level positive air pressure ventilation in patients with stable COPD may reduce end tidal carbon dioxide $\left(\mathrm{E}_{\mathrm{T}} \mathrm{CO}_{2}\right)$ and $\mathrm{HR}$ and increase peripheral oxygen saturation $\left(\mathrm{SpO}_{2}\right)$ [4].

Neme et al. evaluated acute treatment with different CPAP levels in patients with stable COPD and found an improvement in ventilation and respiratory mechanics [24]. Although treatment with different modes of NIV has been used and considered effective for improvement in ventilatory mechanics, autonomic modulation and quality of life in patients with COPD, the effect of different CPAP levels on the autonomic control of heart rate in patients with stable COPD remains unclear [25].

The hypothesis of the present study was that acute treatment with CPAP would have an effect on autonomic balance and respiratory function and the effects of CPAP treatment on heart rate variability (HRV) would be closely related to the levels applied. Thus, the aim of this study was to investigate autonomic modulation in patients with COPD and CHF submitted to acute treatment with different levels of CPAP.

\section{Material and methods}

\section{Study population}

The procedures used in this study were in accordance with the recommendations of the Helsinki Declaration [26]. All subjects provided written informed consent before entering the study. The protocol received approval from the Ethics Committee of the Universidade Federal de São Carlos, São Paulo, Brazil. After all evaluations and procedures, a total of 28 male patients were divided into three groups: 10 patients with COPD, 8 patients with $\mathrm{CHF}$ and 10 healthy controls. All patients were submitted to the following evaluations: clinical and laboratory examinations, classification of dyspnoea, New York Heart Association (NYHA) functional classification, pulmonary function tests and electrocardiography (ECG).

The following were the inclusion criteria for the COPD group: diagnosis from a physician; forced expiratory volume in one second $\left(\mathrm{FEV}_{1}\right) /$ forced vital capacity (FVC) ratio $<0.7$ and $\mathrm{FEV}_{1}<60 \%$ of predicted; clinical stability for at least three months; absence of current smoking habit; dyspnoea during low and medium physical effort; and dyspnoea during daily activities (Medical Research Council score of I-III). The following were the inclusion criteria for the CHF group: diagnosis from a physician; echocardiogram with left ventricular ejection fraction < 50\%; NYHA classification score of I-III; FEV $\mathrm{FEV}_{1} / \mathrm{FV}$ and $\mathrm{FEV}_{1}>70 \%$ of predicted. The control group was made up of healthy, sedentary individuals, as determined by the clinical classification of the American Heart Association [29]. Patients receiving medications are described in Table I.

\section{Design and procedures}

A double-blinded, randomized, cross-sectional study was carried out. R-R intervals (R-Ri) and physiological variables were collected for $10 \mathrm{~min}$ during spontaneous breathing and with three CPAP levels: sham ventilation (Sham), $5 \mathrm{cmH}_{2} \mathrm{O}$ (CPAP5) and $10 \mathrm{cmH}_{2} \mathrm{O}$ (CPAP10).

\section{Measurements}

\section{Lung function}

Spirometric tests were performed using a portable spirometer (Hand Held 2120, Vitalograph, 
Table I. Anthropometric characteristics, lung function, MRC and NYHA class, echocardiography, cause of heart failure and medications in control group (CG), chronic heart failure (CHF) group and chronic obstructive pulmonary disease (COPD) group

\begin{tabular}{|c|c|c|c|}
\hline Variable & CG $(n=10)$ & $\mathrm{CHF}(n=8)$ & $\operatorname{COPD}(n=10)$ \\
\hline \multicolumn{4}{|l|}{ Anthropometric characteristics } \\
\hline Age [years] & $64 \pm 5$ & $62 \pm 8$ & $69 \pm 9$ \\
\hline Height [m] & $1.71 \pm 0.05$ & $1.66 \pm 0.07$ & $1.67 \pm 8.96$ \\
\hline Weight $[\mathrm{kg}]$ & $74 \pm 6$ & $69 \pm 10$ & $64 \pm 8^{*}$ \\
\hline $\mathrm{BMI}\left[\mathrm{kg} / \mathrm{m}^{2}\right]$ & $25 \pm 1$ & $24 \pm 3$ & $23 \pm 3$ \\
\hline \multicolumn{4}{|l|}{ Lung function } \\
\hline FEV1 (\% predicted) & $91 \pm 20.0$ & $81 \pm 9.1$ & $40 \pm 10.9^{*}$ \\
\hline FEV1/CVF & $101 \pm 7.0$ & $82 \pm 4.2$ & $58 \pm 11.8^{*}$ \\
\hline \multicolumn{4}{|l|}{ MRC / NYHA class } \\
\hline I & & 1 & 1 \\
\hline II & & 4 & 3 \\
\hline III & & 3 & 6 \\
\hline \multicolumn{4}{|l|}{ Echocardiogram } \\
\hline Left ventricular ejection fraction [\%] & & $39 \pm 9$ & \\
\hline \multicolumn{4}{|l|}{ Cause of heart failure } \\
\hline Ischaemic dilated cardiomyopathy & & 3 & \\
\hline Idiopathic/non-ischaemic dilated cardiomyopathy & & 5 & \\
\hline \multicolumn{4}{|l|}{ Medications, $n$ (\%) } \\
\hline Bronchodilators & & & $10(100)$ \\
\hline Beta-blockers & & $8(100)$ & \\
\hline Digoxin & & $5(62.5)$ & \\
\hline Nitrates & & $2(25)$ & \\
\hline Angiotensin-converting enzyme inhibitors & & $7(87.5)$ & \\
\hline Furosemide, $n(\%)$ & & $3(37.5)$ & \\
\hline Acetylsalicylic acid, $n$ (\%) & & $2(25)$ & \\
\hline
\end{tabular}

Data are presented as mean $\pm S D$

MRC denotes classification of dyspnoea; NYHA denotes functional classification of New York Heart Association

* Significant inter-group differences between COPD group vs. CG

Ennis, Ireland). $\mathrm{FEV}_{1}$ and maximal voluntary ventilation were determined and compared to predicted normal values following methods described elsewhere [21,30].

\section{Non-invasive ventilation protocol}

Mechanical ventilatory assistance was delivered using a CPAP device (Breas PV101, Sweden) and administered through a comfortably fitting face mask (Respironics, Murrysville, PA, USA). NIV was randomized and set individually for each patient in the following manner: Sham - breathing at minimal pressure to experience resistance from the equipment; CPAP5 - breathing at $5 \mathrm{cmH}_{2} \mathrm{O}$ of positive pressure; CPAP10 - breathing at $10 \mathrm{cmH}_{2} \mathrm{O}$ of positive pressure. The capnometer was attached to the orifice in the nasal mask (BCl-1050,
Waukesha, USA). During NIV, the subjects were instructed to relax, breathe calmly and maintain a respiratory rate similar to spontaneous breathing during CPAP ventilation, which was visually displayed by the capnometer located in clear view directly in front of the subjects. There was an initial adaptation period (30 min) for the first randomized CPAP level. After this period, physiological and HRV parameters were recorded during $10 \mathrm{~min}$. A 10-minute rest period was given between other randomized settings.

\section{Physiological measurements}

$\mathrm{SpO}_{2}$ was continuously monitored using portable pulse oximetry (Oxifast, Takaoka, Brazil). $\mathrm{E}_{\mathrm{T}} \mathrm{CO}_{2}$ and respiratory rate $(R R)$ were determined using a capnometer and recorded every 10 seconds as 
well as at the end of the procedures. Systolic blood pressure (SBP) and diastolic blood pressure (DBP) were measured using an indirect method and were analysed at baseline as well as during the last $30 \mathrm{~s}$ of the protocol. HRV was recorded using the Polar system (S810i). The digitally coded R-Ri length was continuously transferred to the Polar Precision Performance software, which displays an HR tachogram on the monitor. Patients were also monitored using a thoracic MC5 lead (cardiac monitor Ecafix TC500, São Paulo, SP, Brazil) to simultaneously obtain the HR in order to evaluate the signals on the monitor to exclude movement artefacts and ectopic beats prior to the HRV analysis.

\section{HRV analysis}

For the HRV analysis, the most stable sections containing 256 points within the 10 min were selected. HRV was analysed in the time (RMSSD the square root of the sum of the squares of the differences between adjacent normal to normal intervals; and SDNN - the standard deviation of normal to normal intervals) and frequency domains $[31,32]$. Absolute and normalized units and low/high frequency ratios were also calculated [3].

\section{Statistical analysis}

The data are presented as mean \pm SD after testing for normal distribution (KolmogorovSmirnov). The sample size was calculated using the GraphPad StatMate software, version 1.01. Based on a pilot study, the target number of patients was calculated to be 10 in each group, with a $5 \%$ type I error, a 2-sided test and 90\% power to detect a $5 \%$ change in $\mathrm{E}_{\mathrm{T}} \mathrm{CO}_{2}$ between spontaneous breathing and the different CPAP levels. These calculations were based on the mean $\mathrm{E}_{\mathrm{T}} \mathrm{CO}_{2}$ difference required for clinical significance. Intergroup differences were evaluated using one-way analysis of variance (ANOVA) with Tukey's post-hoc test. The level of significance was set at $5 \%$. The analysis was carried out using the Statistical Package for the Social Sciences.

\section{Results}

Figure 1 shows the sample loss of each studied group. Table I displays the mean values of the demographic and anthropometric characteristics of the sample, pulmonary function, classification of dyspnoea, echocardiogram, cause of heart failure and medications used in the CHF and COPD groups.

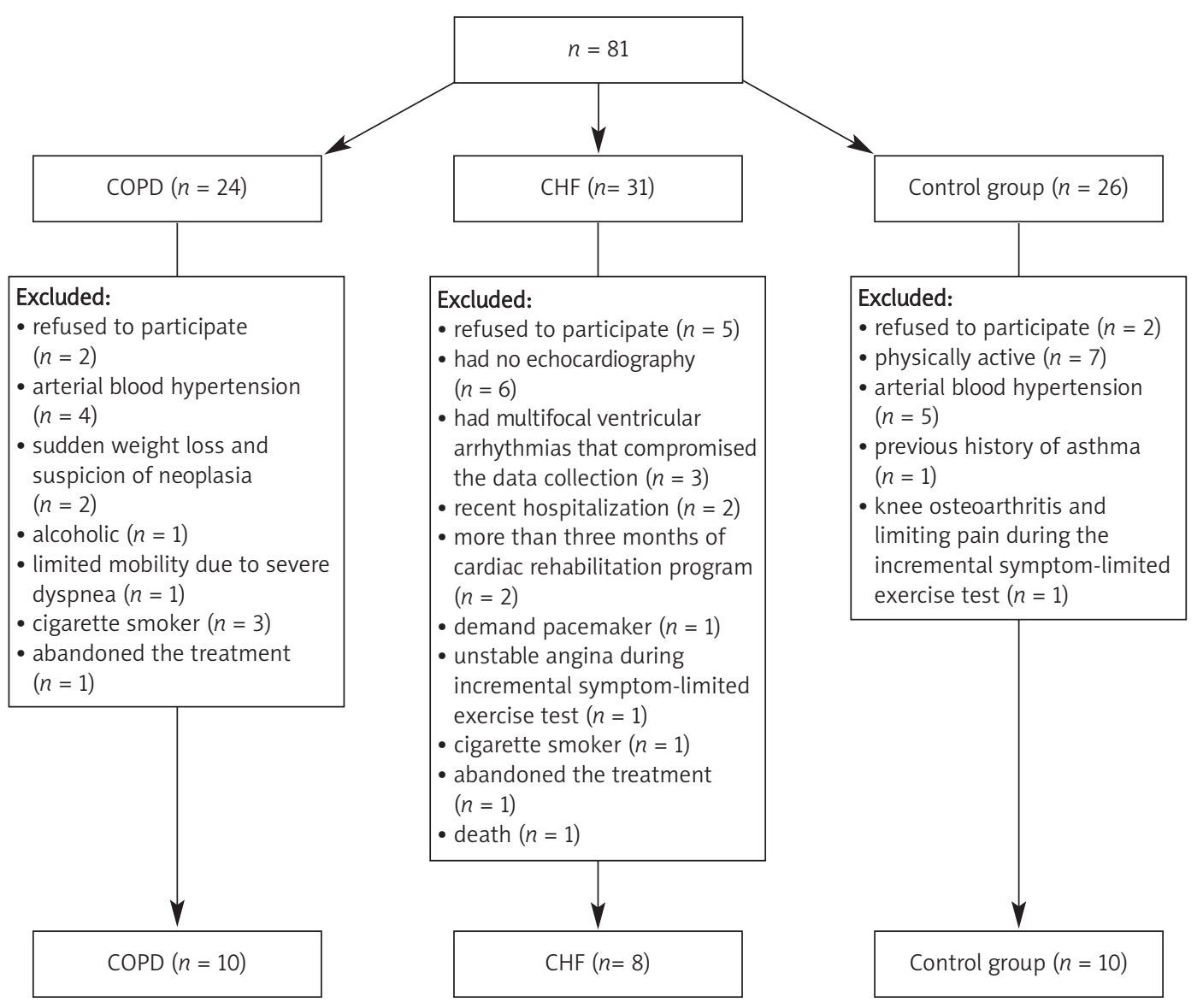

Figure 1. Flowchart - sample loss of each studied group 
No significant differences were found between groups regarding age, height and body mass index (BMI). However, the COPD group had a significantly lower body mass when compared to the control group. As expected, patients with COPD had moderate-to-severe forms of the disease [28].

\section{Effects of CPAP on physiological variables}

No significant intra-group differences were found in RR between spontaneous breathing and the different CPAP levels in the control and CHF groups. However, a significant reduction in RR was found in the COPD group with all different CPAP levels when compared to spontaneous breathing ( $p<0.05)$. Moreover, RR during spontaneous breathing was higher in the COPD group when compared to the control group $(p<0.05)$. A significant reduction in $\mathrm{E}_{\mathrm{T}} \mathrm{CO}_{2}$ was found during treatment with CPAP in all groups. In the COPD group, higher CPAP levels led to a greater reduction in $\mathrm{E}_{\mathrm{T}} \mathrm{CO}_{2}$. In the $\mathrm{CHF}$ group, a significant reduction only occurred in the treatment with CPAP $10 \mathrm{cmH}_{2} \mathrm{O}$ when compared to spontaneous breathing and sham CPAP (Table II). A significant increase in $\mathrm{SpO}_{2}$ was found in the COPD group during treatment with the different CPAP levels when compared to spontaneous breathing. Moreover, $\mathrm{SpO}_{2}$ in the COPD group was significantly lower than that in the control and CHF groups under all conditions (Table II). In the intra-group comparisons, a significant reduction in DBP was found during the sham CPAP and CPAP5 in the control group alone. Significantly lower SBP values in the CHF group were found during spontaneous breathing, sham CPAP and CPAP10 when compared to the control and COPD groups (Table II).

\section{Effects of CPAP on HRV}

A significant increase in $\mathrm{HR}$ occurred during treatment with sham CPAP and $5 \mathrm{cmH}_{2} \mathrm{O}$ compared to spontaneous breathing in the COPD group. During treatment with CPAP 5 and $10 \mathrm{cmH}_{2} \mathrm{O}$, higher $\mathrm{HR}$ values were found in the COPD group when compared to the CHF group (Table III). In the time domain, significantly lower RMSSD values during treatment with different CPAP levels when compared to spontaneous breathing were found in the COPD group alone (Figure 2). Moreover, significantly lower RMSSD values were found during treatment with different CPAP levels in the COPD group when compared to the control group (Table III). In the CHF group, significant increases in SDNN and power spectral density were found during treatment with CPAP 5 and $10 \quad \mathrm{cmH}_{2} \mathrm{O}$ when compared to spontaneous breathing (Figure 2). In the inter-group comparisons, lower SDNN values were found in the COPD group during treatment with CPAP $10 \mathrm{cmH}_{2} \mathrm{O}$ when compared to the control group (Table III). No significant intra-group differences in R-Ri values were found during treatment with the different CPAP levels when compared to spontaneous breathing. In the inter-group comparisons, higher R-Ri values during treatment with the different CPAP levels were found in the COPD group when compared to the control group.

\section{Discussion}

The important novel finding of the present study is that treatment with higher CPAP levels induced greater adjustment in autonomic function in patients with COPD and CHF. CPAP $5 \mathrm{cmH}_{2} \mathrm{O}$ led to an improvement in ventilation with no imbalance in autonomic heart rate modulation in patients with COPD. However, acute treatment with CPAP10 altered autonomic regulation, leading to an increase in sympathetic activity and a reduction in parasympathetic activity in patients with COPD. Moreover, the best responses in ventilation and autonomic balance in patients with CHF seem to be with CPAP10.

Table II. Physiological variables in control group (CG), chronic heart failure (CHF) group and chronic obstructive pulmonary disease (COPD) group during spontaneous breathing (SB) and different CPAP levels

\begin{tabular}{|c|c|c|c|c|c|c|c|c|c|c|c|c|}
\hline \multirow[t]{2}{*}{ Variable } & \multicolumn{4}{|c|}{ CG $(n=10)$} & \multicolumn{3}{|c|}{$\mathrm{CHF}(n=8)$} & \multicolumn{5}{|c|}{$\operatorname{COPD}(n=10)$} \\
\hline & SB & Sham & CPAP5 & CPAP10 & SB & Sham & CPAP5 & CPAP10 & SB & Sham & CPAP5 & CPAP10 \\
\hline RR [bpm] & $12 \pm 3^{*}$ & $12 \pm 2$ & $13 \pm 3$ & $13 \pm 3$ & $15 \pm 2$ & $13 \pm 3$ & $13 \pm 3$ & $13 \pm 3$ & $18 \pm 4$ & $14 \pm 4^{a}$ & $15 \pm 3^{a}$ & $14 \pm 3^{a}$ \\
\hline $\mathrm{ETCO} 2\left[\mathrm{cmH}_{2} \mathrm{O}\right]$ & $38 \pm 4$ & $35 \pm 4^{a}$ & $31 \pm 6^{a}$ & $30 \pm 5^{a, c}$ & $38 \pm 3$ & $35 \pm 5$ & $31 \pm 6$ & $31 \pm 6^{a, c}$ & $35 \pm 5$ & $32 \pm 5^{a}$ & $29 \pm 5 a, b$ & $27 \pm 6^{a, c, d}$ \\
\hline $\mathrm{SpO}_{2}[\%]$ & $97 \pm 1^{*}$ & $97 \pm 1^{*}$ & $97 \pm 1^{*}$ & $97 \pm 1^{*}$ & $96 \pm 2^{\dagger}$ & $97 \pm 1^{\dagger}$ & $97 \pm 1^{\dagger}$ & $97 \pm 1^{\dagger}$ & $92 \pm 3$ & $94 \pm 2^{a}$ & $94 \pm 2^{\mathrm{a}}$ & $95 \pm 3^{a}$ \\
\hline $\mathrm{SBP}[\mathrm{mmHg}]$ & $120 \pm 8^{\ddagger}$ & $117 \pm 9^{\star \neq}$ & $117 \pm 9$ & $118 \pm 7^{\star \neq}$ & $106 \pm 13^{\dagger}$ & $106 \pm 9^{\dagger}$ & $107 \pm 8$ & $107 \pm 7^{\dagger}$ & $120 \pm 7$ & $118 \pm 9$ & $116 \pm 9$ & $117 \pm 8$ \\
\hline $\mathrm{DBP}[\mathrm{mmHg}]$ & $78 \pm 4$ & $74 \pm 7 a$ & $74 \pm 7 a$ & $76 \pm 5$ & $71 \pm 10$ & $71 \pm 8$ & $70 \pm 9$ & $69 \pm 9$ & $72 \pm 8$ & $72 \pm 8$ & $73 \pm 8$ & $74 \pm 8$ \\
\hline
\end{tabular}

Data are presented as mean $\pm S D$, Sham - breathing at $3 \mathrm{cmH}_{2} \mathrm{O}, \mathrm{CPAP5}$ - breathing at $5 \mathrm{cmH}_{2} \mathrm{O}$ positive pressure, CPAP1O - breathing at $10 \mathrm{CmH}_{2} \mathrm{O}$ positive pressure, $R R$ - respiratory rate, $E_{T} \mathrm{CO}_{2}$ - end tidal carbon dioxide, $\mathrm{SpO}_{2}$ - peripheral oxygen saturation, $S B P-s y s t o l i c$ blood pressure, $D B P$ - diastolic blood pressure, asignificant intra-group differences compared to $S B$, bsignificant intra-group differences between Sham and CPAP5, 'significant intra-group differences between Sham and CPAP10, dsignificant intra-group differences between CPAP10 and CPAP5, *significant inter-group differences between COPD group and CG, ${ }^{\ddagger}$ significant inter-group differences between CHF group and CG, ${ }^{\dagger}$ significant inter-group differences between COPD and CHF groups 


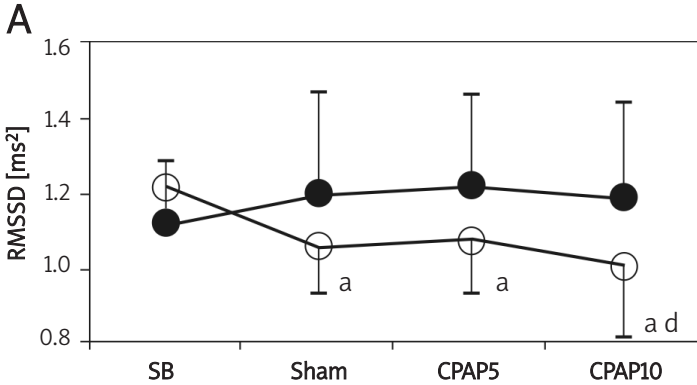

B

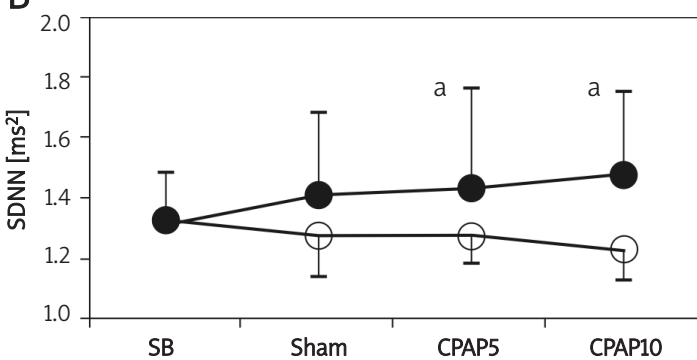

C

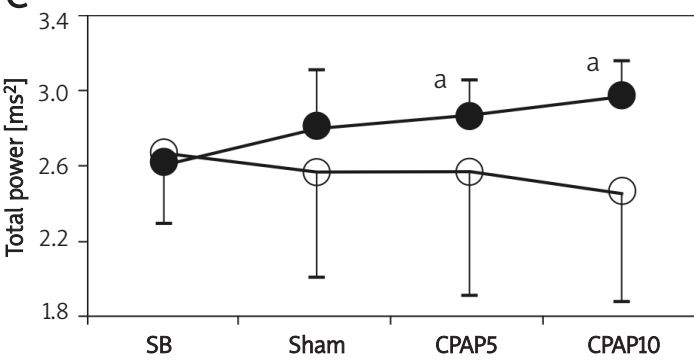

O COPD group

- CHF group

Figure 2. Heart rate variability during spontaneous breathing (SB) and different CPAP levels

asignificant intra-group differences compared to $S B$,

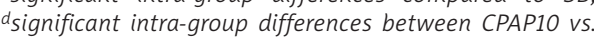
CPAP5, Data are presented as mean $\pm S D$, Sham - breathing at $3 \mathrm{CmH}_{2} \mathrm{O}, \mathrm{CPAP5}$ - breathing at $5 \mathrm{CmH}_{2} \mathrm{O}$ positive pressure, CPAP1O - breathing at $10 \mathrm{CmH}_{2} \mathrm{O}$ positive pressure, RMSSD (ms) index - SDNN index

These findings indicate the presence of a "best CPAP level" in the short-term administration of noninvasive CPAP acting on the modulation of autonomic tone and respiratory responses. New strategies and careful titration for finding the "best CPAP level' for individual patients is very important, as patients with COPD and CHF have autonomic heart dysfunction related to an increased risk of cardiovascular events and mortality $[7,15]$.

\section{Effects of CPAP on ventilatory parameters and autonomic balance of $\mathrm{HR}$}

Patients with COPD and CHF have a considerable reduction in lung function, which exacerbates the impact of the illness [33, 34]. Acute CPAP treatment in patients with stable COPD reduces symptoms of dyspnoea as well as RR and $\mathrm{E}_{\mathrm{T}} \mathrm{CO}_{2}$ values. In COPD, the respiratory system is primarily hampered by the additional elastic load associated with dynamic hyperinflation and intrinsic positive end-expiratory pressure (PEEP). These factors predispose patients to respiratory failure by increasing the load on the respiratory muscles, while decreasing their mechanical efficiency and capacity for generating maximal pressure [35].

In the present study, CPAP likely reduced the respiratory load imposed by intrinsic PEEP. When proximal airway pressure is elevated by CPAP to a level approaching the intrinsic PEEP, the inspiratory muscles only need to lower alveolar pressure to the CPAP level to initiate inspiration.

Previous studies have demonstrated that RR and $\mathrm{E}_{\mathrm{T}} \mathrm{CO}_{2}$ can modulate $\operatorname{HRV}[4,36]$. In the present study, a significant reduction was found in the $\mathrm{HF}$ band and RMSSD index, along with an increase in the LF band during acute treatment with CPAP10 in patients with COPD, indicating an imbalance in autonomic control. The HF band and RMSSD components are both generally defined as markers of vagal modulation and the LF band has been associated with sympathetic activity [3]. In this autonomic adaptation, the increase in sympathetic activity and reduction in parasympathetic activity may not be favourable, as it has been related to physiopathological diseases, arrhythmia and an increased risk of mortality [2, 3]. Interestingly, when the patients with COPD were submitted to acute treatment with CPAP5, the same responses in ventilatory parameters and autonomic balance occurred, with a reduction only in the RMSSD index. Moreover, this reduction in RMSSD was significantly lower than that during CPAP10. These results indicate that acute treatment with CPAP5 is safer than CPAP10, probably due to inducing lesser imbalance in autonomic tone in patients with stable COPD.

In the patients with $\mathrm{CHF}$, acute treatment with different levels of CPAP promoted few changes in respiratory function and autonomic balance. During acute treatment with CPAP5 there were no changes in respiratory response when compared to spontaneous breathing. However, there was a significant increase in the SDNN index. $A$ reduction in this index is an independent predictor of mortality [3, 37]. Interestingly, acute treatment with CPAP10 caused a significant reduction in $\mathrm{E}_{\mathrm{T}} \mathrm{CO}_{2}$ and an increase in the SDNN index at the same proportion as CPAP5. Moreover, CPAP10 led to a significant increase in total power of spectral density, which reflects a mixture of both autonomic inputs $[3,12]$. Based on these acute responses, treatment with CPAP10 offers greater advantages and safety in patients with CHF. There is a clear association between reduced HRV and 
Table III. Heart rate variability values in time domain (TD) and frequency domain (FD) of control group (CG), chronic heart failure (CHF) group and chronic obstructive pulmonary disease (COPD) group during spontaneous breathing (SB) and different CPAP levels

\begin{tabular}{|c|c|c|c|c|c|c|c|c|c|c|c|c|}
\hline \multirow[t]{2}{*}{ HRV Index } & \multicolumn{5}{|c|}{ CG $(n=10)$} & \multicolumn{4}{|c|}{$\operatorname{CHF}(n=8)$} & \multicolumn{3}{|c|}{$\operatorname{COPD}(n=10)$} \\
\hline & SB & Sham & CPAP5 & CPAP10 & SB & Sham & CPAP5 & CPAP10 & SB & Sham & CPAP5 & CPAP10 \\
\hline \multicolumn{13}{|l|}{ TD } \\
\hline $\mathrm{HR}$ [bpm] & $\begin{array}{c}1.83 \\
\pm 0.06\end{array}$ & $\begin{array}{c}1.82 \\
\pm 0.05\end{array}$ & $\begin{array}{c}1.83 \\
\pm 0.05^{\star}\end{array}$ & $\begin{array}{c}1.83 \\
\pm 0.06^{*}\end{array}$ & $\begin{array}{c}1.82 \\
\pm 0.06\end{array}$ & $\begin{array}{c}1.82 \\
\pm 0.04\end{array}$ & $\begin{array}{c}1.82 \\
\pm 0.04^{\dagger}\end{array}$ & $\begin{array}{c}1.82 \\
\pm 0.04^{\dagger}\end{array}$ & $\begin{array}{c}1.86 \\
\pm 0.07\end{array}$ & $\begin{array}{c}1.86 \\
\pm 0.07\end{array}$ & $\begin{array}{c}1.89 \\
\pm 0.06\end{array}$ & $\begin{array}{c}1.92 \\
\pm 0.06^{\mathrm{a}, \mathrm{c}, \mathrm{d}}\end{array}$ \\
\hline R-Ri [ms] & $\begin{array}{c}2.95 \\
\pm 0.06\end{array}$ & $\begin{array}{c}2.95 \\
\pm 0.05^{*}\end{array}$ & $\begin{array}{c}2.96 \\
\pm 0.05^{\star}\end{array}$ & $\begin{array}{c}2.95 \\
\pm 0.06^{*}\end{array}$ & $\begin{array}{c}2.94 \\
\pm 0.07\end{array}$ & $\begin{array}{c}2.91 \\
\pm 0.04\end{array}$ & $\begin{array}{c}2.91 \\
\pm 0.04\end{array}$ & $\begin{array}{c}2.90 \\
\pm 0.03\end{array}$ & $\begin{array}{c}2.92 \\
\pm 0.07\end{array}$ & $\begin{array}{c}2.89 \\
\pm 0.07\end{array}$ & $\begin{array}{c}2.89 \\
\pm 0.07\end{array}$ & $\begin{array}{c}2.88 \\
\pm 0.06\end{array}$ \\
\hline RMSSD [ms] & $\begin{array}{c}1.29 \\
\pm 0.14\end{array}$ & $\begin{array}{c}1.36 \\
\pm 0.25^{*}\end{array}$ & $\begin{array}{c}1.34 \\
\pm 0.15^{*}\end{array}$ & $\begin{array}{c}1.30 \\
\pm 0.21^{*}\end{array}$ & $\begin{array}{c}1.12 \\
\pm 0.10\end{array}$ & $\begin{array}{c}1.20 \\
\pm 0.13\end{array}$ & $\begin{array}{c}1.22 \\
\pm 0.14\end{array}$ & $\begin{array}{c}1.19 \\
\pm 0.19\end{array}$ & $\begin{array}{c}1.22 \\
\pm 0.17\end{array}$ & $\begin{array}{c}1.06 \\
\pm 0.27 \mathrm{a}\end{array}$ & $\begin{array}{c}1.08 \\
\pm 0.25^{a}\end{array}$ & $\begin{array}{c}1.01 \\
\pm 0.26^{\mathrm{a}, \mathrm{d}}\end{array}$ \\
\hline SDNN [ms] & $\begin{array}{c}1.46 \\
\pm 0.13\end{array}$ & $\begin{array}{c}1.48 \\
\pm 0.19\end{array}$ & $\begin{array}{c}1.45 \\
\pm 0.16\end{array}$ & $\begin{array}{c}1.47 \\
\pm 0.19^{\star}\end{array}$ & $\begin{array}{c}1.31 \\
\pm 0.06\end{array}$ & $\begin{array}{c}1.41 \\
\pm 0.16\end{array}$ & $\begin{array}{c}1.44 \\
\pm 0.09 \mathrm{a}\end{array}$ & $\begin{array}{c}1.48 \\
\pm 0.10^{\mathrm{a}}\end{array}$ & $\begin{array}{c}1.33 \\
\pm 0.18\end{array}$ & $\begin{array}{c}1.28 \\
\pm 0.28\end{array}$ & $\begin{array}{c}1.28 \\
\pm 0.33\end{array}$ & $\begin{array}{c}1.23 \\
\pm 0.28\end{array}$ \\
\hline \multicolumn{13}{|l|}{ FD } \\
\hline PSD & $\begin{array}{c}2.93 \\
\pm 0.26\end{array}$ & $\begin{array}{c}2.96 \\
\pm 0.38^{\star}\end{array}$ & $\begin{array}{c}2.90 \\
\pm 0.33^{*}\end{array}$ & $\begin{array}{c}2.94 \\
\pm 0.39^{*}\end{array}$ & $\begin{array}{c}2.62 \\
\pm 0.12\end{array}$ & $\begin{array}{c}2.81 \\
\pm 0.31\end{array}$ & $\begin{array}{c}2.87 \\
\pm 0.19 \mathrm{a}\end{array}$ & $\begin{array}{c}2.97 \\
\pm 0.20^{a}\end{array}$ & $\begin{array}{c}2.67 \\
\pm 0.37\end{array}$ & $\begin{array}{c}2.57 \\
\pm 0.55\end{array}$ & $\begin{array}{c}2.57 \\
\pm 0.65\end{array}$ & $\begin{array}{c}2.46 \\
\pm 0.57\end{array}$ \\
\hline $\mathrm{LF}\left[\mathrm{ms}^{2}\right]$ & $\begin{array}{c}2.38 \\
\pm 0.32^{*}\end{array}$ & $\begin{array}{c}2.50 \\
\pm 0.40\end{array}$ & $\begin{array}{c}2.41 \\
\pm 0.33\end{array}$ & $\begin{array}{c}2.57 \\
\pm 0.41^{*}\end{array}$ & $\begin{array}{c}2.06 \\
\pm 0.20\end{array}$ & $\begin{array}{c}2.37 \\
\pm 0.46\end{array}$ & $\begin{array}{c}2.29 \\
\pm 0.39\end{array}$ & $\begin{array}{c}2.45 \\
\pm 0.40\end{array}$ & $\begin{array}{c}1.84 \\
\pm 0.58\end{array}$ & $\begin{array}{c}1.90 \\
\pm 0.69\end{array}$ & $\begin{array}{c}1.89 \\
\pm 0.79\end{array}$ & $\begin{array}{c}1.89 \\
\pm 0.63\end{array}$ \\
\hline $\mathrm{HF}\left[\mathrm{ms}^{2}\right]$ & $\begin{array}{c}2.17 \\
\pm 0.28\end{array}$ & $\begin{array}{c}2.31 \\
\pm 0.54\end{array}$ & $\begin{array}{c}2.27 \\
\pm 0.32\end{array}$ & $\begin{array}{c}2.10 \\
\pm 0.45\end{array}$ & $\begin{array}{c}1.81 \\
\pm 0.30\end{array}$ & $\begin{array}{c}1.90 \\
\pm 0.39\end{array}$ & $\begin{array}{c}1.98 \\
\pm 0.37\end{array}$ & $\begin{array}{c}1.93 \\
\pm 0.56\end{array}$ & $\begin{array}{c}1.90 \\
\pm 0.40\end{array}$ & $\begin{array}{c}1.62 \\
\pm 0.46\end{array}$ & $\begin{array}{c}1.60 \\
\pm 0.49\end{array}$ & $\begin{array}{c}1.55 \\
\pm 0.51^{a}\end{array}$ \\
\hline LFnu & $\begin{array}{c}1.76 \\
\pm 0.14^{*}\end{array}$ & $\begin{array}{c}1.74 \\
\pm 0.17\end{array}$ & $\begin{array}{c}1.74 \\
\pm 0.10\end{array}$ & $\begin{array}{c}1.86 \\
\pm 0.06^{\mathrm{a}, \mathrm{c}, \mathrm{d}, \mathrm{d}, *}\end{array}$ & $\begin{array}{c}1.80 \\
\pm 0.11\end{array}$ & $\begin{array}{c}1.82 \\
\pm 0.13\end{array}$ & $\begin{array}{c}1.77 \\
\pm 0.16\end{array}$ & $\begin{array}{c}1.82 \\
\pm 0.17\end{array}$ & $\begin{array}{c}1.60 \\
\pm 0.30\end{array}$ & $\begin{array}{c}1.80 \\
\pm 0.11\end{array}$ & $\begin{array}{c}1.79 \\
\pm 0.16\end{array}$ & $\begin{array}{c}1.82 \\
\pm 0.10^{\mathrm{a}}\end{array}$ \\
\hline HFnu & $\begin{array}{c}1.55 \\
\pm 0.22\end{array}$ & $\begin{array}{c}1.55 \\
\pm 0.28\end{array}$ & $\begin{array}{c}1.60 \\
\pm 0.20\end{array}$ & $\begin{array}{c}1.39 \\
\pm 0.16\end{array}$ & $\begin{array}{c}1.50 \\
\pm 0.24\end{array}$ & $\begin{array}{c}1.36 \\
\pm 0.39\end{array}$ & $\begin{array}{c}1.47 \\
\pm 0.38\end{array}$ & $\begin{array}{c}1.30 \\
\pm 0.45\end{array}$ & $\begin{array}{c}1.64 \\
\pm 0.30\end{array}$ & $\begin{array}{c}1.52 \\
\pm 0.16\end{array}$ & $\begin{array}{c}1.49 \\
\pm 0.22\end{array}$ & $\begin{array}{c}1.48 \\
\pm 0.19\end{array}$ \\
\hline LF/HF ratio & $\begin{array}{c}0.21 \\
\pm 0.36\end{array}$ & $\begin{array}{c}0.19 \\
\pm 0.44\end{array}$ & $\begin{array}{c}0.14 \\
\pm 0.29\end{array}$ & $\begin{array}{c}0.47 \\
\pm 0.22\end{array}$ & $\begin{array}{c}0.26 \\
\pm 0.30\end{array}$ & $\begin{array}{c}0.47 \\
\pm 0.52\end{array}$ & $\begin{array}{c}0.30 \\
\pm 0.53\end{array}$ & $\begin{array}{c}0.52 \\
\pm 0.61\end{array}$ & $\begin{array}{l}-0.07 \\
\pm 0.62\end{array}$ & $\begin{array}{c}0.28 \\
\pm 0.28\end{array}$ & $\begin{array}{c}0.29 \\
\pm 0.38\end{array}$ & $\begin{array}{c}0.34 \\
\pm 0.29\end{array}$ \\
\hline
\end{tabular}

Data are presented as mean $\pm \mathrm{SD}$, Sham - breathing at $3 \mathrm{CmH}_{2} \mathrm{O}, \mathrm{CPAP5}$ - breathing at $5 \mathrm{CmH}_{2} \mathrm{O}$ positive pressure, CPAP1O - breathing at $10 \mathrm{CmH}_{2} \mathrm{O}$ positive pressure, $H R$ - heart rate, $R$ - $\mathrm{Ri}$ - electrocardiographic $\mathrm{R}$ - $\mathrm{R}$ intervals, RMSSD - root mean square of successive differences in $R$ - $R$ intervals in ECG, SDNN - standard deviation of normal $R$-R intervals in ECG, PSD - total power spectral density, $L F-l o w$ frequency, $H F$ - high frequency, LFnu - normalized LF units, HFnu - normalized HF units, LF/HF ratio - global sympathovagal balance, a significant intragroup differences compared to SB, csignificant intra-group differences between Sham and CPAP10, dsignificant intra-group differences between CPAP10 and CPAP5, "significant inter-group differences between COPD group and CG, ${ }^{\dagger}$ significant inter-group differences between COPD and CHF groups

poor outcomes in a number of chronic and acute heart diseases [38].

The different pressure levels administered were enough to improve $\mathrm{SpO}_{2}$ in the patients with COPD, whereas no changes occurred in the healthy subjects or patients with CHF. As expected, lower $\mathrm{SpO}_{2}$ levels at rest were found in the patients with COPD. These conditions during walking and exercise are a critical problem during rehabilitation [20, 39]. Moreover, CPAP has been used in the treatment of a number of diseases, particularly COPD and obstructive sleep apnoea [2, 39, 40].

In the present study, acute treatment with CPAP increased $\mathrm{SpO}_{2}$ and did not alter $\mathrm{BP}$ in patients with COPD. Moreover, no alterations in BP occurred in patients with $\mathrm{CHF}$ during acute treatment with CPAP. Ensuring $\mathrm{SpO}_{2}$ and maintaining $\mathrm{BP}$ is favourable to haemodynamic responses. While CPAP is effective in treating diverse acute and chronic conditions, its benefits to BP remain unclear [40].
Treatment with different levels of CPAP did not alter HR in any of the groups, except the COPD group during treatment with $10 \mathrm{cmH}_{2} \mathrm{O}$. Although automaticity is intrinsic to different cardiac tissues with pacemaker properties, the HR and contractile activity of the myocardium are largely modulated by sympathetic and vagal outflows [1]. Acute treatment with CPAP5 and 10 decreased the RMSSD index in patients with COPD, which is predominantly vagally mediated, reflected in an increase in HR [3]. The decrease in the RMSSD component was significantly lower during acute treatment with $5 \mathrm{CmH}_{2} \mathrm{O}$.

Regarding the limitations of the present study, it should be taken into consideration that the patients with CHF were receiving beta-blockers and the COPD group was using bronchodilators, which could have influenced the outcome. However, we intended to evaluate these patients under real-life conditions. Additionally, more studies are necessary 
to evaluate women under the same COPD and $\mathrm{CHF}$ conditions.

Autonomic dysfunction, an increase in sympathetic activity and a reduction in parasympathetic activity have been reported in patients with COPD and CHF. These dysfunctions are associated with physiopathological diseases, arrhythmia and an increased risk of cardiovascular events and mortality. CPAP has been extensively used as an effective component during rehabilitation in this population, as it improves ventilatory parameters, haemodynamics and autonomic balance. The findings of the present study reveal that treatment with different levels of CPAP promotes different autonomic responses. Thus, finding an individual's "best CPAP level" increases the safety and efficiency of treatment.

In conclusion, these findings suggest that CPAP may improve the neural control of heart rate in patients with stable COPD and CHF. For each patient, a "best CPAP level" should be defined in association with the greatest ventilatory response and autonomic balance. In cases in which two or more CPAP levels resulted in a better ventilatory response and sympathetic activity, the "best CPAP" was the level associated with the greatest ventilatory response and the least reduction in parasympathetic activity.

\section{Acknowledgements}

The authors would like to thank the Brazilian fostering agency Conselho Nacional de Desenvolvimento Científico e Tecnológico for providing financial support. More importantly, however, the authors are indebted to the patients for their effort and enthusiastic cooperation throughout the study.

\section{References}

1. Pinsky MR. Cardiovascular issues in respiratory care. Chest 2005; 128 (Suppl. 2): 592S-7S.

2. Chrysostomakis SI, Simantirakis EN, Schiza SE, et al. Continuous positive airway pressure therapy lowers vagal tone in patients with obstructive sleep apnoea-hypopnoea syndrome. Hellenic J Cardiol 2006; 47: 13-20.

3. Sztajzel J. Heart rate variability: a noninvasive electrocardiographic method to measure the autonomic nervous system. Swiss Med Wkly 2004; 134: 514-22.

4. Borghi-Silva A, Reis MS, Mendes RG, et al. Noninvasive ventilation acutely modifies heart rate variability in chronic obstructive pulmonary disease patients. Respir Med 2008; 102: 1117-23.

5. Brochard L, Mancebo J, Wysocki M, et al. Noninvasive ventilation for acute exacerbations of chronic obstructive pulmonary disease. N Engl J Med 1995; 333: 817-22.

6. Nelesen RA, Yu H, Ziegler MG, Mills PJ, Clausen JL, Dimsdale JE. Continuous positive airway pressure normalizes cardiac autonomic and hemodynamic responses to a laboratory stressor in apneic patients. Chest 2001; 119: 1092-101.
7. Kaye DM, Mansfield D, Aggarwal A, Naughton MT, Esler $M D$. Acute effects of continuous positive airway pressure on cardiac sympathetic tone in congestive heart failure. Circulation 2001; 103: 2336-8.

8. Frazier SK, Moser DK, Schlanger R, Widener J, Pender L, Stone KS. Autonomic tone in medical intensive care patients receiving mechanical ventilation and during a CPAP weaning trial. Biol Res Nurs 2008; 9: 301-10.

9. Fietze I, Romberg D, Glos M, et al. Effects of positivepressure ventilation on the spontaneous baroreflex in healthy subjects. J Appl Physiol 2004; 96: 1155-60.

10. Garet M, Barthelemy JC, Degache F, Pichot V, Duverney $D$, Roche F. Modulations of human autonomic function induced by positive pressure-assisted breathing. Clin Physiol Funct Imaging 2006; 26: 15-20.

11. Kaneko Y, Floras JS, Usui K, et al. Cardiovascular effects of continuous positive airway pressure in patients with heart failure and obstructive sleep apnea. N Engl J Med 2003; 348: 1233-41.

12. Butler GC, Naughton MT, Rahman MA, Bradley TD, Floras JS. Continuous positive airway pressure increases heart rate variability in congestive heart failure. J Am Coll Cardiol 1995; 25: 672-9.

13. Naughton MT, Rahman MA, Hara K, Floras JS, Bradley TD. Effect of continuous positive airway pressure on intrathoracic and left ventricular transmural pressures in patients with congestive heart failure. Circulation 1995; 91: 1725-31.

14. Yan AT, Bradley TD, Liu PP. The role of continuous positive airway pressure in the treatment of congestive heart failure. Chest 2001; 120: 1675-85.

15. Volterrani M, Scalvini S, Mazzuero G, et al. Decreased heart rate variability in patients with chronic obstructive pulmonary disease. Chest 1994; 106: 1432-7.

16. Scalvini S, Porta R, Zanelli E, et al. Effects of oxygen on autonomic nervous system dysfunction in patients with chronic obstructive pulmonary disease. Eur Respir J 1999; 13: 119-24.

17. Tukek T, Yildiz P, Atilgan D, et al. Effect of diurnal variability of heart rate on development of arrhythmia in patients with chronic obstructive pulmonary disease. Int I Cardiol 2003; 88: 199-206.

18. Highcock MP, Shneerson JM, Smith IE. Increased ventilation with NilPPV does not necessarily improve exercise capacity in COPD. Eur Respir J 2003; 22: 100-5.

19. Toledo A, Borghi-Silva A, Sampaio LM, Ribeiro KP, Baldissera V, Costa D. The impact of noninvasive ventilation during the physical training in patients with moderate-to-severe chronic obstructive pulmonary disease (COPD). Clinics 2007; 62: 113-20.

20. Hawkins P, Johnson LC, Nikoletou D, et al. Proportional assist ventilation as an aid to exercise training in severe chronic obstructive pulmonary disease. Thorax 2002; 57: 853-9.

21. Standardization of Spirometry, 1994 Update. American Thoracic Society. Am J Respir Crit Care Med 1995; 152: 1107-36.

22. Ries AL, Bauldoff GS, Carlin BW, et al. Pulmonary Rehabilitation: Joint ACCP/AACVPR Evidence-Based Clinical Practice Guidelines. Chest 2007; 131 (5 Suppl.): 4S-42S.

23. Ambrosino N, Strambi S. New strategies to improve exercise tolerance in chronic obstructive pulmonary disease. Eur Respir J 2004; 24: 313-22.

24. Neme JY, Gutiérrez AM, Santos MC, et al. Physiologic effects of noninvasive ventilation in patients with chronic obstructive pulmonary disease. Arch Bronconeumol 2007; 43: 150-5.

25. Lightowler JV, Wedzicha JA, Elliott MW, Ram FS. Noninvasive positive pressure ventilation to treat respiratory 
failure resulting from exacerbations of chronic obstructive pulmonary disease: Cochrane systematic review and meta-analysis. BMJ 2003; 326: 185.

26. Williams JR. The Declaration of Helsinki and public health. Bull World Health Organ 2008; 86: 650-2.

27. Standards for the diagnosis and care of patients with chronic obstructive pulmonary disease. American Thoracic Society. Am J Respir Crit Care Med 1995; 152 (5 Pt 2): S77-121.

28. Pauwels RA, Buist AS, Calverley PM, Jenkins CR, Hurd SS. Global strategy for the diagnosis, management, and prevention of chronic obstructive pulmonary disease. NHLBI/WHO Global Initiative for Chronic Obstructive Lung Disease (GOLD) Workshop summary. Am J Respir Crit Care Med 2001; 163: 1256-76.

29. Schlant RC, Blomqvist CG, Brandenburg RO, et al. Guidelines for exercise testing. A report of the Joint American College of Cardiology/American Heart Association Task Force on Assessment of Cardiovascular Procedures (Subcommittee on Exercise Testing). Circulation 1986; 74: 653A-67A.

30. Knudson RJ, Lebowitz MD, Holberg CJ, Burrows B. Changes in the normal maximal expiratory flow-volume curve with growth and aging. Am Rev Respir Dis 1983; 127: 725-34.

31. Ramaekers D, Ector H, Aubert AE, Rubens A, Van de Werf F. Heart rate variability and heart rate in healthy volunteers. Is the female autonomic nervous system cardioprotective? Eur Heart J 1998; 19: 1334-41.

32. Malliani A, Pagani M, Lombardi F, Cerutti S. Cardiovascular neural regulation explored in the frequency domain. Circulation 1991; 84: 482-92.

33. Ito K, Barnes PJ. COPD as a disease of accelerated lung aging. Chest 2009; 135: 173-80.

34. Clark AL. Origin of symptoms in chronic heart failure. Heart 2006; 92: 12-6.

35. Reissmann HK, Ranieri VM, Goldberg P, Gottfried SB. Continuous positive airway pressure facilitates spontaneous breathing in weaning chronic obstructive pulmonary disease patients by improving breathing pattern and gas exchange. Intensive. Care Med 2000; 26: 1764-72.

36. Poyhonen M, Syvaoja S, Hartikainen J, Ruokonen E, Takala J. The effect of carbon dioxide, respiratory rate and tidal volume on human heart rate variability. Acta Anaesthesiol Scand 2004; 48: 93-101.

37. Kruger C, Lahm T, Zugck C, et al. Heart rate variability enhances the prognostic value of established parameters in patients with congestive heart failure. Z Kardiol 2002; 91: 1003-12.

38. Galinier M, Pathak A, Fourcade J, et al. Depressed low frequency power of heart rate variability as an independent predictor of sudden death in chronic heart failure. Eur Heart J 2000; 21: 475-82.

39. Dreher M, Storre JH, Windisch W. Noninvasive ventilation during walking in patients with severe COPD: a randomised cross-over trial. Eur Respir J 2007; 29: 930-6.

40. Dimsdale JE, Loredo JS, Profant J. Effect of continuous positive airway pressure on blood pressure: a placebo trial. Hypertension 2000; 35 (1 Pt 1): 144-7.

41. Heart rate variability: standards of measurement, physiological interpretation and clinical use. Task Force of the European Society of Cardiology and the North American Society of Pacing and Electrophysiology. Circulation 1996; 93: 1043-65. 